\title{
Tearing the Fabric: A Critique of Materialism
}

\author{
Passia Pandora* \\ University of Victoria \\ passiapandora@gmail.com
}

\begin{abstract}
One of the long-standing questions in the field of philosophy of mind is called the mind-body problem. The problem is this: given that minds and mental properties appear to be vastly different than physical objects and physical properties, how can the mind and body relate to and interact with each other? Materialism is the currently preferred response to philosophy's classic mind-body problem. Most contemporary philosophers of mind accept a materialist perspective with respect to the nature of reality. They believe that there is one reality and it is physical. One of the primary problems with materialism has to do with the issue of physical reduction, that is, if everything is physical, how does the mental reduce to the physical? I argue that the materialistic model is problematic because it cannot sufficiently explain the reduction problem. Specifically, the materialist model does not account for our subjective experience, including qualia. I also consider the question of why the materialist stance is so entrenched, given all the problems with the reduction problem that have been raised. I argue that the paradigmatic influence of materialism explains the puzzling conclusions drawn by philosophers. In closing, I argue that the failure of materialist perspectives to explain reduction is our invitation to take a fresh look at the alternatives.
\end{abstract}

Keywords: mind-body problem; materialism; physical reduction; qualia; paradigm

$\mathrm{T}$ he dominant metaphysical commitment among philosophers in the 21st century is that of materialism. Materialism, also known as physicalism, is a theory which holds that everything that exists is physical (Stoljar, 2017). Physical objects have size, shape, location, solidity, and motion, and their interactions are determined by the laws of physics (Calef, n.d.). Materialists acknowledge that biological, psychological, social, or moral "items" may appear to be non-physical, but they argue that those items are either physical or they supervene ${ }^{1}$ on the physical (Stoljar, 2017). Materialism is the currently preferred response to philosophy's classic mind-body problem (Mandik, 2014). The mind-body problem is this: given that minds and mental properties (such as pain) appear to be vastly different from physical objects and physical properties, how can the mind and body relate to and interact with each other (Mandik, 2014, p. 7)? More specifically, philosophers ask, If mental things are just physical things, how can that be explained? That is, how do mental things reduce to physical things (Mandik, 2014, p. 7)? The materialist response to the mind-body problem is that, ultimately, everything is reduced to something physical.

In spite of the popularity of materialism among philosophers in the field of philosophy of mind, there are many problems with the reduction stance. The problem of reduction is not an obscure

* This research was supported by the Jamie Cassels Undergraduate Research Award, University of Victoria. I extend my appreciation to Prof. Klaus Jahn and Dr. Eric Hochstein for their generous assistance and support in this project. I also wish to thank the editor of the Arbutus Review and the anonymous reviewers of my paper for their valuable feedback.

${ }^{1} \mathrm{~A}$ set of properties "A" supervenes upon another set of properties "B" if and only if no two things can differ with respect to A-properties without also differing with respect to their B-properties (McLaughlin \& Bennett, 2018). 
question that is of interest only to philosophers; it has repercussions that extend far beyond the field of philosophy. Materialism is a metaphysical commitment that can be considered as an entire package of views: it represents a "Physicalist World Picture" (Stoljar, 2017, Physicalism and the Physicalist World Picture, para. 1). Materialism is the lens that we currently use to understand the world and our place in it; it forms the foundation of all our physical and social sciences. The disciplines of biology, cognitive science, physics, artificial intelligence, and psychology, to name a few, are all implicated in their commitment to materialism. If reduction cannot be established in the field of philosophy of mind, the materialist foundation of all science comes into question. Therefore, the question of materialism is not simply a question for consideration; it is the first and primary question that must be considered in all sciences. In this paper, I will argue that the materialistic model is problematic because it cannot sufficiently explain the reduction problem. I believe that there is a credible alternative to materialism, but that discussion is beyond the scope of this paper.

I will present this paper in four sections. In Section One, I will provide a description of two of the currently accepted materialist theories in the field of philosophy of mind: functionalism and eliminativism. Section One is offered primarily to provide some background, context and definitions of terms. In support of my thesis, the materialistic model is problematic because it cannot sufficiently explain the reduction problem, so I will consider the reduction problem in two additional sections. In Section Two, I will present some contemporary arguments put forth by Jaegwon Kim, Ned Block, Thomas Nagel, John Searle, David Chalmers, and Frank Jackson. These contemporary arguments address four different reduction problems. Although the arguments presented by Kim, Block, Searle, Nagel, Chalmers, and Jackson are compelling, I will claim that their arguments have not succeeded in altering the mainstream materialist viewpoint. In this section, I will also present two arguments against eliminativism. In Section Three, I will address three of my concerns regarding the reduction problem: 1) concerns regarding unresolved issues with respect to the reduction problem, 2) concerns that materialism cannot account for common characteristics of our mental experience, and 3) concerns regarding the validity of the materialist stance in general. In Section Four, I will consider the question of why the materialist stance is so entrenched, given all the problems with the reduction problem that have been raised. I will argue that the paradigmatic influence of materialism explains the puzzling conclusions drawn by philosophers. In closing, I will argue that the failure of materialist perspectives to conclusively explain reduction is our invitation to take a fresh look at the alternatives.

\section{Section One: Functionalism and Eliminativism}

In this section, I will provide a description of two of the currently accepted materialist theories in the field of philosophy of mind: functionalism and eliminativism. Functionalism is the most widely accepted view in philosophy of mind today (Levine, 1997). With functionalism, mental states, defined by Yoo (n.d.) as beliefs, desires, feelings or perceptions, are not defined in terms of material substances (Mandik, 2014). Instead, mental states are defined by the causal relations they bear to input states (sensory states), output states (verbal and nonverbal behaviours) and other mental states (Mandik, 2014). For example, the mental state of fear may be triggered by a perception of a potentially harmful thing such as a poisonous snake (the input state). A fearful situation may result in a protective or evasive action, an expressive verbal behaviour, or both (the output state). For example, when you see a snake, you shriek and run away from it. Previously held beliefs (other mental states) about snakes may play a role in how you respond to the snake (Mandik, 2014).

Two frequently cited objections to functionalism are the absent qualia problem and the inverted spectra problem. The term "qualia" refers to the subjective property of our experience (Kind, n.d.). Since it is possible to imagine the existence of an organism that satisfies the same functional states 
as humans, but who has no qualitative experience associated with those functional states, one important objection is that functionalism fails to account for the subjective or qualitative aspect of mental states (Bechtel, 1988). Block (2007) coins this the "Absent Qualia Argument" (p. 73). The inverted spectra problem is this: as Jerry Fodor (1981) explains, functionalism allows for the possibility that two mental states have the same causal relations yet differ in their qualitative content (p. 122). Fodor offers this thought experiment that illustrates the inverted spectra problem:

It seems possible to imagine two observers who are alike in all relevant psychological respects except that experiences having the qualitative content of red for one observer would have the qualitative content of green for the other. Nothing about their behavior need reveal the difference because both of them see ripe tomatoes and flaming sunsets as being similar in color and both of them call that color "red." Moreover, the causal connection between their (qualitatively distinct) experiences and their other mental states could also be identical. (p. 122)

Fodor concludes that the functionalist view cannot account for the differences in the qualitative experience of each observer. Because mental states are not defined in terms of material substances, functions are multiply realizable; that is, they can be realized in more than one way ${ }^{2}$. When a property is multiply realizable, there is no one physical property of which the experience of pain can be identified with (Ney, n.d.). For example, the pain experienced by a human and a dog may be the same, but the human body and the dog body realize that pain differently. Because functionalism is compatible with multiple-realizability, it allows for the possibility that mental states could be realized in non-physical ways. Therefore, in theory, functionalism is consistent with non-physicalist theories. However, functionalism is primarily considered from a physicalist perspective (Mandik, 2014). Because a function must eventually be conceived in terms of a physical process (Ney, n.d.), reduction remains a concern 3 Therefore, from the physicalist perspective, multiple-realizability represents a reduction problem.

Eliminative materialism (EM; also known as eliminativism) is an extreme form of physicalist monism. Physical monism suggests that everything in reality, including mind and consciousness, is or can be reduced to something physical (Kriegel, 2007). EM theorists hold that our common-sense understanding of the mind is deeply flawed. They argue that some or all of the mental states posited by our common-sense understanding do not actually exist and have no role to play in the science of mind (Ramsey, 2019). These mental states include propositional attitudes (defined by Oppy (1998) as beliefs, hopes, desires, intentions, etc.) and phenomenal or qualitative states, such as the concept of pain (Ramsey, 2019). There are two conceptions of EM theory: strong and weak. Strong EM holds that there are no mental states, only brain states (Ramsey, 2019). Reduction is not a consideration for strong EM theorists; they claim that mental states cannot be reduced to or identified with neuronal events or processes because they hold that mental states do not exist (Ramsey, 2019). In the same way that demons are unreal and have no explanatory role for people who have mental health issues, strong EM theorists argue that mental states are unreal and have no explanatory role in the brain sciences or philosophy (Ramsey, 2019). Strong EM is generally

\footnotetext{
${ }^{2}$ Generally, multiple-realizability exists when it is possible for "the tokens of a certain type to be realized by tokens of two or more distinct types." For example, the function of pain can be realized in more than one way, for example, by c-fibres firing or q-fibres firing (Jaworski, n.d., para.1). When a property is multiply realizable, there is no one physical property by which the experience of pain can be identified with (Ney, n.d.).

${ }^{3}$ Functional reduction requires two stages. First, the phenomena to be reduced is construed relationally. For example, the function "boiling" is construed as the property of a liquid where bubbles appear on the surface and vapor results. Second, the observed property is identified as an outcome of a physically based science. For example, the existence of bubbles and vapor are identified as the outcome of a reduction of atmospheric pressure, which subsequently allows molecules to escape the surface of the liquid (Ney, n.d.).
} 
rejected because it makes a claim that is self-undermining: it recommends that we believe the claim that there are no beliefs (Mandik, 2014). Weak EM holds that there are mental states, but they are just brain states (Ramsey, 2019). Weak EM theorists argue that our common-sense understanding of mental states is flawed; there is no way to reduce or "map" our common-sense understanding of mental states onto a neurological model of the brain (Ramsey, 2019). In the same way that our concept of "weeds" corresponds to something actual, but has no explanatory value in the science of botany, our concepts of mental states may refer to something actual, but have no explanatory value in brain science (Ramsey, 2019). Regardless of the form, strong or weak, eliminative materialists argue that the discussion of mental states falls into the realm of folk psychology (intrinsically held, common-sense beliefs) that are not supported by science (Mandik, 2014). For this reason, eliminative materialists recommend the elimination of any talk of mental entities, such as minds, mental states, and mental properties (Mandik, 2014). Because EM denies the existence of our common-sense understanding of mental states, some philosophers argue that EM does not meet the necessary conditions required of a successful theory of mind. EM theorists reject this idea, arguing that EM liberates us from holding this restrictive perspective (Ramsey, 2019). I will next consider some additional objections to EM.

\section{Section Two: Contemporary Arguments Against Materialism}

In this section, I will present some contemporary arguments put forth by Jaegwon Kim, Ned Block, Thomas Nagel, John Searle, David Chalmers, and Frank Jackson. These contemporary arguments address four different reduction problems. Although the arguments presented by these authors are compelling, I will claim that their arguments have not succeeded in altering the mainstream materialist viewpoint. In this section, I will also present two arguments against eliminativism.

The foundation of the materialist argument is based upon a mechanistic worldview, which holds that there is an objective "outside" world that exists independently from us and that everything in this world is a physical thing or has a physical state. Our world is considered to be objective because it is presumed to exist independently of a subject's perception of it. That is, the objective world exists even if there is no subject to perceive it (Mulder, n.d.). Because our physical reality is a causally closed system, everything in this reality must ultimately have a physical explanation (Kim, 2005). Thus, the mental must be explained in terms of the physical; the mental must be reducible

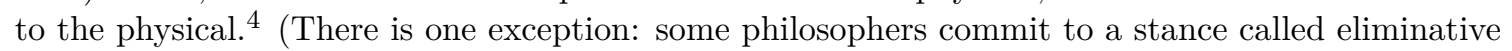
materialism (EM), which denies the existence of the mental altogether. I will discuss EM with respect to the reduction problem later in this paper.) However, reduction is problematic. There are four different reduction problems to consider. First, considering physical reduction, philosophers who dispute materialism have argued that mental states cannot be reduced to physical states (brain states). Second, considering a functional approach where mental states are defined in terms of their causes and effects (Fodor, 1981), philosophers have further argued that mental properties cannot be reduced to physical properties; mental properties such as pain cannot be defined in terms of physical processes. Third, philosophers have argued that when reduction has occurred, there remains some aspect of the mental state that cannot be reduced, thereby rendering the reduction incomplete. Fourth, some philosophers claim that reduction is not a problem; they reject the reality of mental states altogether.

\footnotetext{
${ }^{4}$ There is a philosophical stance called non-reductive physicalism (NPR) that holds that 1) all substances are physical, and 2) mental properties are not reducible to physical properties. However, Susan Schneider (2013) argues that NRP is false because it conflicts with two of the leading views regarding the nature of substance (pp. 135-136). Those views suggest that properties are considered to be metaphysical constituents of substances. Therefore, mental properties cannot be purely physical substances.
} 
Kim (2005) responds to the first and second problems of reduction. Regarding the first problem, the reduction of mental states to physical states, Kim suggests that some materialist philosophers embrace the idea of mind-body supervenience, seeing it as an option that protects the autonomy of the mental without lapsing into dualism, the belief that there are two kinds of "stuff" in the world, mental and physical (Mandik, 2014). That is, they believe that supervenience allows that the mental can be accommodated within the realm of the physical; the mental and the physical are not fundamentally different. However, when the problem of mental causation is considered, Kim writes, "This seductive picture ...turns out to be a piece of wishful thinking" (p. 15). Kim explains that if we accept the principle that our physical system is causally closed, then mental state causation is not possible because all causal explanations are physical causal explanations. That is, it is impossible for mental states to have any physical affect. Regarding the second problem, functional reduction, Kim further argues that mental properties cannot be reduced to physical properties. To reduce mental properties, they must first be functionalized. Kim explains that to functionalize a mental property such as pain, it must be shown that pain is definable as being in a state that is caused by certain inputs (e.g., tissue damage or trauma) and that those inputs bring about certain outputs (e.g., characteristic pain behaviours, a sense of distress, or a desire to be rid of it) (p. 24). However, materialism requires that functional states be realized physically (p. 29). Therefore, Kim concedes that because qualia are "mental residue" that cannot be accommodated in our physical world, they are not functionally definable and are therefore functionally irreducible (pp. 28-29). Concluding that qualia resist functional reduction, Kim writes that "global physicalism is untenable" (p. 170).

Ned Block (2007) gives an argument that offers support for the failure of the second problem of functional reduction of mental properties to physical properties. Block makes a significant contribution to the discussion regarding functionalism and the irreducibility of mental states by introducing a thought experiment that has come to be known as "The Chinese Nation" (Cole, 2019). Block proposes a thought experiment where the physical (neuronal) processes of the brain are represented functionally by creating a network of individual people making two-way radio calls to one another. The calls required no conversations; instead, the calls made are simply meant to mirror a neuronal pattern of interaction that occurs in the brain (Cole, 2019). Therefore, the cognitive process is being functionally represented external to the brain, expressed through the network interactions of a billion people. However, as Block observes, "there is a prima facie doubt whether [the network] has any mental states at all" (p. 73). Block's thought experiment demonstrates that our subjective experience cannot be functionally reduced; it cannot account for qualia.

John Searle's (1980) "Chinese Room" thought experiment also offers support for the failure of the second problem, the functional reduction of mental properties to physical properties. Interestingly, Searle's original intention was to comment on a discussion in the area of artificial intelligence; he first introduced this thought experiment to show conclusively that it is impossible for computers to think or understand language (Cole, 2019). He later developed a broader interpretation that refutes the functionalist approach to understanding mind (Cole, 2019). His thought experiment goes like this: Searle (1980) asks us to imagine a person alone in a room who follows specific instructions on how to respond to Chinese characters that are slipped under the door. Although the person in the room does not understand Chinese, by following the instructions for manipulating symbols and numerals, that person is able to produce strings of Chinese characters that fool the people outside the room into believing that there is a Chinese speaker in the room (p. 418). Searle's original intent was to show that while computers are able to use syntactic rules to manipulate strings of symbols, they have no understanding of the meaning of those symbols. Searle's Chinese Room thought experiment refutes the Computational Theory of Mind, a functionalist theory, because it denies that mental states can be defined by their causal roles (Cole, 2019). Searle (2010) writes, "Computation is defined purely formally or syntactically, whereas minds have actual mental or semantic contents, 
and we cannot get from syntactical to the semantic just by having the syntactical operations and nothing else" (p. 17).

The most common objection to Searle's thought experiment is known as "the systems reply" (Cole, 2019). While the objectors agree that the person in the room does not understand Chinese, they argue that the person in the room is part of a greater system whole that does understand it. Searle's (1980) response to this objection is to say that, in principle, the person in the room could internalize the entire system, but even if they did, that person would still not understand Chinese (p. 419). We still cannot get semantics from syntax. Therefore, the thought experiments offered by both Block and Searle refute functional reduction of the mental to the physical. Curiously, although Block and Searle both refute functional reduction, they do not refute materialism. Searle (2010) argues that conscious states are caused by brain processes and are realized in the brain. Block (2007) argues that although functionalism and physicalism are incompatible, functionalism (if it is true) does not show that physicalism is false.

Thomas Nagel (1974) offers another argument that demonstrates the failure of the third reduction problem, the problem of incomplete reduction. In Nagel's (1974) essay "What Is It Like to Be a Bat," he suggests that mental states cannot be completely reduced to physical states because the quality of "what it is like" to be a bat (or a human) is left out (p. 436). The quality of "what it is like" refers to the subjective aspect of our experiences in life (e.g., the taste of a sweet cinnamon bun, the smell of grass after a rain, a musical note that hangs in the air and then fades away). According to Nagel, the physical system cannot account for the subjective point-of-view (p. 442). And, since every phenomenal experience is subjective, it cannot be accounted for by a physical state which is necessarily objective. Thus, no amount of physical information can tell us what it is like to be a bat (Jackson, 1982, p. 131). Nagel (1974) writes,

If physicalism is to be defended, the phenomenological features must themselves be given a physical account. But when we examine their subjective character it seems that such a result is impossible. The reason is that every subjective phenomenon is essentially connected with a single point of view, and it seems inevitable that an objective, physical theory will abandon that point of view. (p. 437)

Nagel's argument is important, so I will unpack it in more detail. First, Nagel observes that the phenomena of conscious experience is widespread, and that for any organism that has a conscious experience, "there is something it is like to be that organism" (p. 436). He calls this the "subjective character of experience" (p. 436). Nagel claims that since functional states could be ascribed to robots or automata who behave like people, but have no subjective experience, the subjective character of experience cannot be analyzed according to these states. Because this subjective character is not analyzable with respect to any system of functional states, Nagel claims that the "recently devised reductive analyses of the mental" (p. 436) do not capture this subjective aspect of experience. In fact, Nagel points out that these reductions are actually "logically compatible with [the subjective character of experience's] absence" (p. 436). Therefore, he argues that materialism cannot be defended using an analysis that fails to explicitly deal with the subjective character of experience (p. 437). In support of this conclusion, Nagel makes a distinction between the subjective (first person) and objective (third person) character of experience. He argues that experience can never have an objective character, writing, "After all, what would be left of what it is like to be a bat if one removed the viewpoint of the bat?" (p. 443). Nagel also observes that the process of reduction requires a shift toward greater objectivity and less upon any specific individual point of view. Reduction works well when we are referring to concepts and ideas that we use to refer to things beyond ourselves (p. 444). However, when it comes to our subjective experience, Nagel argues that reduction makes no logical sense. It is not possible to move toward greater objectivity 
while maintaining our subjective experience. Nagel writes,

If the subjective character of experience is fully comprehensible from one point of view, then any shift to greater objectivity - that is, less attachment to a specific viewpoint - does not take us nearer to the real nature of the phenomenon: it takes us farther away from it. (pp. 444-445)

This is especially apparent when it comes to species-specific viewpoints. Nagel claims that the species-specific viewpoint must be excluded for reduction to succeed (p. 445). Finally, Nagel concludes that, if we accept that a physical theory of mind accounts for our subjective character of experience, then we currently have no conception about how it makes this account (p. 445).

David Chalmers (1995) offers another perspective regarding the third problem, incomplete reduction. Because the physical is all there is, materialists must explain mental functions in terms of physical processes. While some mental functions can be explained as physical processes, others cannot. Chalmers distinguishes between these, naming them the easy and hard problems of consciousness, respectively (p. 200). The easy problems are those that can be explained in terms of physical processes or neural mechanisms. The hard problems are those that cannot. Some examples of the easy problems of consciousness identified by Chalmers are the ability to discriminate, categorize, and react to environmental stimuli; the integration of information by a cognitive system; the reportability of mental states; the ability of a system to access its own internal states; the focus of attention; the deliberate control of behaviour; and the difference between wakefulness and sleep (p. 200). They are considered "easy" because each of these functions can be described by a physical process or mechanism. Alternatively, Chalmers considers subjective experience to be the "really hard problem of consciousness" (p. 201). In his discussion, Chalmers also explains why the easy problems are easy and the hard problem is hard. The easy problems, ones that define cognitive processes and mechanisms, can be explained from an objective perspective. The hard problem, our subjective experience, cannot be described objectively. Chalmers (1995) writes,

The easy problems are easy precisely because they concern the explanation of cognitive abilities and functions. To explain a cognitive function, we need only specify a mechanism that can perform the function. The methods of cognitive science are well-suited for this sort of explanation, and so are well-suited to the easy problems of consciousness. By contrast, the hard problem is hard precisely because it is not a problem about the performance of functions. The problem persists even when the performance of all the relevant functions is explained. (p. 202)

Therefore, as with Kim, Chalmers argues that because subjective experience cannot be functionalized, subjective experience extends beyond functional performance; subjective experience cannot be reduced (p. 203). When applied to subjective experience, Chalmers considers the reductive method to be "impotent" (p. 208). In spite of this conclusion, Chalmers posits a materialist theory which he calls "naturalistic dualism," where consciousness is considered to be fundamental and therefore irreducible, yet is somehow explained by physical laws (p. 210).

Frank Jackson (1982) offers an argument that also demonstrates the failure of the third problem, the problem of incomplete reduction. Jackson approaches the reduction problem from a different angle. His contribution has come to be known as "The Knowledge Argument" (Nida-Rümelin, 2015). Jackson suggests that there are certain kinds of perceptual experiences that cannot be accounted for using purely physical information. There is something missing: our subjective, phenomenal experience. Jackson (1982) explains, 
Tell me everything physical there is to tell about what is going on in a living brain, the kind of states, their functional role, their relation to what goes on at other times and in other brains, and so on and so forth and be I as clever as can be in fitting it all together, you won't have told me about the hurtfulness of pains, the itchiness of itches, pangs of jealousy, about the characteristic experience of tasting a lemon, smelling a rose, hearing a loud noise or seeing the sky. (p. 127)

Jackson introduces two examples to explain his knowledge argument. In one of Jackson's examples, he introduces us to Mary. Mary is a brilliant neurophysiologist who, for whatever reason, is "forced to investigate the world from a black and white room via a black and white television monitor" (p. 130). As a specialist in vision, Mary knows everything about the physical aspects of sight. Next, Jackson poses the question, "What will happen when Mary is released from her black and white room or is given a color television monitor? Will she learn anything or not?" (p. 130). Jackson concludes that is seems "obvious" that she will learn something new (p. 130). Therefore, even when Mary had all the physical information, it must be that her previous knowledge was incomplete. Therefore, once again, physicalism leaves something out. Thus, in both cases, Jackson argues that "qualia are left out of the physicalist story" (p. 130). There have been many objections to the Knowledge Argument. One common objection, known as the New Knowledge/Old Fact view suggests that when Mary learns what it is like to see red, she does not learn a new fact, but instead learns an old fact in a new way. Therefore, a new piece of knowledge does not necessarily infer the existence of a new fact (Kriegel, 2007). A similar version of this objection is called the "ability reply," which suggests that the only knowledge Mary gains is "know-how" or skill. Mary gains no new knowledge of physical facts (Van Gulick, 1997, p. 560). Van Gulick (1997) explains, "[Mary] gains only new practical abilities to recognize and imagine the relevant phenomenal properties" (p. 560). While Van Gulick accepts that Mary gains know-how, he also suggests that know-how is not all that she gains. She also "apprehends" a fact about phenomenal red after her release (p. 560). In spite of his observation, Van Gulick nevertheless argues that Mary's knowledge can be reduced to the physical. Following Brian Loar's argument, Van Gulick suggests that Mary acquires a concept "that enters her cognitive repertoire," which she is able to use to realize the truth of new propositions (pp. 562-563). Loar and Gulick argue that this is not problematic for the physicalist because the property to which the new concept refers is one that exists within the realm of the physical sciences (pp. 562-563). In light of these objections, Jackson's Knowledge Argument remains controversial (Nida-Rümelin, 2015).

The fourth problem to consider with respect to reduction is specific to eliminative materialism (EM). Recall that both forms of EM, strong and weak, are physically monistic. Thus, EM theorists avoid the reduction problem by denying the reality of anything mental. Strong EM holds that there are no mental states, only brain states. The reduction problem is not a consideration for strong EM theorists; they claim that mental states cannot be reduced to or identified with neuronal events or processes because they hold that mental states do not exist (Ramsey, 2019). Weak EM holds that there may be mental states, but they are just brain states (Ramsey, 2019). Weak EM theorists reject the reduction of mental states to neuronal states, claiming that the concept of mental states has no explanatory value in the brain sciences. In fact, Kathleen Wilkes (1984) suggests that consciousness is "not important at all" in the neurosciences and that philosophers of mind should not bother exploring the notion (p. 224). Some EM theorists have not only questioned the reality of particular states of consciousness, but also question the existence of consciousness itself (Ramsey, 2019). They argue that consciousness is an illusion (Ramsey, 2019). They contend that awareness and subjectivity are probably neuronal effects. For example, EM theorists Rick Grush and Patricia Churchland (1995) argue that "consciousness is almost certainly a property of the physical brain" (p. 10). In response, I offer two objections. First, the stance that our conscious 
experience is simply an illusion is extremely counter-intuitive. As Joseph Levine (1997) writes, "it is difficult to see how one can maintain that qualitative character isn't a genuine property of my experience" (pp. 398-400). Second, there is a logical error with this claim. Even the experience of an illusion is an experience. A being that is not conscious can have no experience whatsoever, including an illusory experience. Therefore, the fact that we seem to have a conscious experience guarantees that we are having a conscious experience (Poole, 2016). As Dennett \& Searle (1995) observe, "where consciousness is concerned, the existence of the appearance is the reality" (para. 10). The illusion assertion reveals a fundamental problem with physically monistic theories - they cannot account for subjectivity. According to Nagel (1986), subjectivity is an irreducible feature of reality; without it, we could not "do physics or anything else" (p. 8) (including philosophy). I will further address the issue of subjectivity in Section Three.

In this section I presented a survey of some of the current arguments that dispute the reduction problem (that the mental can be reduced to the physical), along with some of the objections to those arguments. Although the arguments presented by Kim, Block, Searle, Nagel, Chalmers, and Jackson are compelling, they have not succeeded in altering the mainstream materialist view. In contemporary literature, philosophers continue to both defend and refute these iconic arguments.

\section{Section Three: Additional Concerns Regarding the Reduction Issue}

In this section, I will consider three of my concerns regarding the reduction issue: 1) concerns regarding unresolved issues with respect to the reduction problem, 2) concerns that materialism cannot account for common characteristics of our mental experience and, 3) concerns regarding the validity of the materialist stance in general.

There are three unresolved issues with respect to the reduction problem. First, functionalists and eliminativists are begging the question. Functionalists argue that the mental reduces to the physical. EM theorists argue that mental states just are brain states. Although materialism is not yet proven, both theories presume that materialism is true. For example, Daniel Dennett (1991) writes,

Somehow the brain must be the mind, but unless we can come to see in some detail how this is possible, our materialism will not explain consciousness, but only promise to explain it, some sweet day. (p. 42, emphasis added)

However, just because we want something to be true, does not make it so. As Kim (2005) suggests, "our wish to save mental causation, however sincere and righteous, cannot by itself make reductionism true" (p. 148). Dennett's comment highlights a second issue. Although philosophers have been unable to prove the reduction of the mental to the physical, they trust that the answers will come sometime in the future once more research is done. Here, they are relying on some predictive power of the future; their arguments are not decisive here and now. As Ramsey (2019) writes, "for eliminative materialism to get off the ground, we need to assume that scientific psychology is going to turn out a certain way. But why suppose that before scientific psychology gets there?" (Concluding Remarks, para. 2). Philosophers have rushed to closure on materialism before closure is warranted.

My second concern is that materialism cannot account for a number of common characteristics of our mental experience. In the first section I discussed qualia, one of those characteristics. In this section, I will discuss some of the other common characteristics that are unaccounted for. Presently, materialism does not account for the subjective, first-person perspective. Nagel (1986) argues that the objective, physical world contains no point of view. However, each of us has the experience of being a particular person in a particular place with a personal view of the world ("The view from 
nowhere," n.d.). That is, we experience reality from a particular point-of-view (POV). POV is a pre-condition for subjective experience and everything that relies upon it, including intentionality, agency (free will), personal narrative, and indexicality. I will briefly consider each of these aspects.

POV allows for an experience of "otherness"; it allows for the separation of self and other or object. For this reason, mental processes have the capacity to be about something. This is Brentano's concept of intentionality (Huemer, 2019). In fact, mental processes always represent something (e.g., a cup of tea, my cat, the clouds (Mandik, 2014)). Conversely, physical processes, having no point-of-view, are not about anything. As Raymond Tallis (1999) writes, "The plenum of the mechanistic world of unconscious matter and unconscious energy lacks 'aboutness'" (p. 238).

POV creates the possibility for agency (free will). According to Schlosser (2015), an agent is a being with the capacity to act. Therefore, agency is the manifestation of the capacity to act, and human agency or free will involves intentional action. We experience agency as an "experience of conscious will" (The sense of agency, para. 2). The concept of human agency is inconsistent with the physicalist, causal model of reality where all interactions are determined based upon the mechanical processing of inputs and outputs (Tallis, 1999). Tallis defends this premise by arguing that a mechanical process does not require the intervention of consciousness or deliberate intention because it occurs according to physical laws (e.g., cause and effect). Mechanistic outcomes happen; they are not brought about through volition. Contrary to volitional acts, the outcomes of mechanistic acts are guaranteed (Tallis, 1999, p. 212). If every nerve impulse is determined by physical laws, how can there be any volition? (Davies \& Brown, 1986). Tallis (1999) asserts that the physical world makes no allowance for a point-of-view and therefore provides no basis for purpose, function or goals; the physical world provides no basis for agency (p. 227).

Tallis (1999) claims that, because it provides for the separation of self and other, POV creates the possibility of personal human narrative, the story of our lives (p. 256). Each of us has our own unique story that includes our experiences, our relationships, our joys and sorrows, and our triumphs and failures. Narrative requires that we separate our environment into a foreground and background of experience. There can be no story without this separation. Tallis explains that consciousness is required to establish a distinction between foreground and background, between organism and environment. Conversely, unconscious organisms have no environment. From a physical, third-person stance, there is no subject of the story; in fact, there is no story at all. As Tallis writes, "we cannot pick a narrative thread ... out of the universe viewed with a steady physicalist gaze" (p. 256). This is the case because, as Tallis explains, "physicalism is egalitarian; all pieces of matter are equivalent" (p. 256). This equivalence denies the possibility of establishing a foreground and background (Tallis, 1999, p. 256). Mechanistic processes have no environments.

Points-of-view are necessary for indexical referencing. Indexical references are ones that are context-specific (Braun, 2017). Examples of indexicals include "I," "here," "today," "yesterday," "he," "she," and "that" (Braun, 2017). The use of indexicals involve treating oneself as a centre or "privileged coordinate" (McGinn, 1983, p. 16). That is, indexicals are agent-centered (Rysiew, 2019). Conversely, objective descriptions of reality are impartial and centreless. Therefore, Tallis (1999) asserts that a properly objective conception of the world must exclude indexicality; objective reality is viewpointless (p. 229). It allows for no here-or-now, no me-or-you, no particularity; that is, no uniqueness or individuality ("Particularity," n.d.), and no identity. Regarding the objective mind, Tallis (1999) writes,

Its world is an existentially unsaturated one of general operations and general possibilities: here-less, now-less, particular-less, this-less, me-less. It lacks conscious identity —it does not exist from its own point of view, for it has nothing to establish a point of view- to lay down the co-ordinates of here and now from which all the absolutes of actuality extend. (p. 230) 
Therefore, indexical cognition and perception requires an agent and a POV. For the reasons discussed above, the third-person perspective of physical reality cannot account for our first-person, subjective, human experiences of intentionality, agency, personal narrative, or indexicality.

My third concern has to do with the validity of the materialist stance in general. I offer two points to consider. First, the materialist stance is based upon the analogy that past successes in the physical sciences of biology and chemistry lend support to the validity of the materialist theory (E. Hochstein, personal communication, fall 2018). However, I argue that this analogy is weak. Previous successes in science come from the objective physical processes of the physical sciences - defined by Goff, Seager, and Allen-Hermanson (2017) as extrinsic, relational, mathematical, or dispositional-processes that exclude the subjective, intrinsic aspects, which are the aspects under consideration here. There are other differences too. As I mentioned previously, mental processes have the capacity to be about something, whereas physical processes do not. The dissimilar nature of the subjective and objective and the differences of intentionality combine to invalidate any comparison. This weak analogy makes the inference uncogent. Second, regarding the validity of the materialist stance, functionalists and eliminativists choose materialism because they see no other plausible options (Kim, 2005, p. 71). For example, regarding functional reduction, Kim (2005) concedes that qualia resist functional reduction and concludes that physicalism is untenable (p. 170). However, he concludes that because qualia are not causally efficacious, the irreducibility of qualia is a minor concern. Kim presents his theory as "slightly defective physicalism," accepting the limitations because he sees no other credible alternative to physicalism as a worldview (p. 174). Kim argues that, by rejecting physicalism, we must embrace non-material substances with non-physical properties such as minds or souls. For Kim, the immaterial is not credible. He writes,

But what options are there if we set aside the physicalist picture? Leaving physicalism behind is to abandon ontological physicalism, the view that bits of matter and their aggregates in space-time exhaust the contents of the world. This means that one would be embracing an ontology that posits entities other than material substances - that is, immaterial minds, or souls, outside physical space, with immaterial, non-physical properties. (p. 71)

There are two points to make here. First, a belief that there are no known plausible alternatives is not a valid reason to accept a theory without reservation. As I mentioned in the Introduction, I believe that there is a credible alternative to materialism. Second, Kim is begging the question when he argues that the immaterial is not credible. The immaterial may not be a credible option for a materialist, but may very well be a credible option for a non-materialist.

\section{Section Four: Why the Rush to Closure?}

Before offering my closing remarks, I would like to address an important question. In Section Two, I remarked that Nagel, Block, and Chalmers accept materialism in spite of their arguments against reduction. Recall that Block and Searle both refute functional reduction, yet they do not refute materialism. Chalmers commits to non-reductive physicalism in spite of arguing that physical reduction methods are impotent. In Section Three, I shared conclusions by Kim and Dennett that seem to rush to closure on the question of materialism even when they concede that problems remain. Specifically, Kim commits to physicalism in spite of his arguments against physical reduction. Dennett commits to physicalism in spite of the fact that physical reduction cannot be proven yet. My question is, with respect to materialism, why is there such a rush to closure? I argue that this outcome has to do with the nature of scientific paradigms. Thomas Kuhn (1996) defines a scientific paradigm as "a universally recognized scientific achievement that for a time provide(s) 
model problems and solutions to a community of practitioners" (p. x). Materialism is such a paradigm. Kuhn observes that paradigms become "firmly embedded" in our educational institutions and therefore exert a "deep hold" on the minds of scientists (p. 5). This paradigmatic influence is so strong that, when confronted with anomalies, instead of rejecting the paradigm, Kuhn asserts that scientists will "devise numerous articulations and ad hoc modifications" to the existing theory in an attempt to eliminate or minimize any apparent conflict (p. 78). I argue that this paradigmatic influence provides an explanation for the puzzling conclusions drawn by Kim, Dennett, Nagel, Block, Chalmers, and others. It is easy to see why the materialist paradigm maintains such a strong hold. A change of paradigm necessitates a monumental body of work. Kuhn suggests that when a new paradigm is adopted, the affected field of study must be reconstructed, a process that requires changes to the most elementary and fundamental theoretical generalizations of the field (p. 85). Kuhn asserts that no new paradigm will be considered until there is awareness of an anomaly and an alternative paradigm is available to take the place of the existing paradigm (p. 77). I argue that the reduction problem reveals an anomaly within the materialist paradigm.

In conclusion, regarding the materialist stance, I argue that philosophers should not rush into a premature and unreserved conclusion. Dennett (1991) suggests that our philosophical failures are failures of imagination, not insight (p. 17). Of course, Dennett is suggesting that we need to be more imaginative regarding a materialist perspective. However, I argue that we need imagination and insight to see that the unwavering and unreserved acceptance of the materialist perspective is the problem. The failure of materialist perspectives to explain reduction is our invitation to take a fresh look at the alternatives. As Tallis (1999) suggests, by staying open, we create the possibility of remaining available to ask new questions and receive new answers (p. xv). 
The Arbutus Review • $2019 \bullet$ Vol. 10, No. 1 • https://doi.org/10.18357/tar101201918931

\section{References}

Bechtel, W. (1988). Philosophy of mind: An overview for cognitive science. Hillsdale, NJ: Erlbaum Associates.

Block, N. J. (2007). Collected papers. Cambridge, MA: MIT Press.

Braun, D. (2017). Indexicals. In E. N. Zalta (Ed.), The Stanford Encyclopedia of Philosophy. Retrieved from https://plato.stanford.edu/archives/sum2017/entries/indexicals/

Calef, S. (n.d.). Dualism and mind. In J. Fieser \& B. Dowden (Eds.), International Encyclopedia of Philosophy. Retrieved from https://www.iep.utm.edu/dualism/

Chalmers, D. J. (1995). Facing up to the problem of consciousness. Journal of Consciousness Studies, 2(3), 200-219.

Cole, D. (2019). The Chinese Room argument. In E. N. Zalta (Ed.), The Stanford Encyclopedia of Philosophy. Retrieved from https://plato.stanford.edu/archives/spr2019/entries/chineseroom/

Davies, P. C. W., \& Brown J. R. (1986). The ghost in the atom: A discussion of the mysteries of quantum physics. Cambridge, UK: Cambridge University Press.

Dennett, D. C. (1991). Consciousness explained (1st ed.). Boston, MA: Little, Brown and Co.

Dennett, D. C. \& Searle, J. R. (1995). The mystery of consciousness: An exchange. New York, NY: The New York Review of Books. Retrieved from https://www.nybooks.com/articles/1995/12/ 21/the-mystery-of-consciousness-an-exchange/

Fodor, J. A. (1981). The mind-body problem. Scientific American, 244(1), 114-123. doi:10.1038/ scientificamerican0181-114

Goff, P., Seager, W., \& Allen-Hermanson, S. (2017). Panpsychism. In E. N. Zalta (Ed.), The Stanford Encyclopedia of Philosophy. Retrieved from https://plato.stanford.edu/archives/win2017/ entries/panpsychism/

Grush, R., \& Churchland, P. S. (1995). Gaps in Penrose's toiling. Journal of Consciousness Studies, 2(1), 10-29.

Huemer, W. (2019). Franz Brentano. In E. N. Zalta (Ed.), The Stanford Encyclopedia of Philosophy. Retrieved from https://plato.stanford.edu/archives/spr2019/entries/brentano/

Jackson, F. (1982). Epiphenomenal qualia. The Philosophical Quarterly, 32(127), 127-136. doi: $10.2307 / 2960077$

Jaworski, W. (n.d.). Mind and multiple realizability. In J. Fieser \& B. Dowden (Eds.), International Encyclopedia of Philosophy. Retrieved August 19, 2019 from https://www.iep.utm.edu/multrea/

Kim, J. (2005). Physicalism, or something near enough. Princeton, NJ: Princeton University Press.

Kind, A. (n.d.). Qualia. In J. Fieser \& B. Dowden (Eds.), International Encyclopedia of Philosophy. Retrieved August 19, 2019 from https://www.iep.utm.edu/qualia/.

Kriegel, U. (2007). A philosophical theories of consciousness: Contemporary western perspectives. In P. D. Zelazo, M. Moscovitch, \& E. Thompson (Eds.), The Cambridge handbook of consciousness (pp. 35-66), Cambridge, UK: Cambridge University Press.

Kuhn, T. S. (1996). The structure of scientific revolutions (3rd ed.). Chicago, IL: University of Chicago Press.

Levine, J. (1997). Recent work on consciousness. American Philosophical Quarterly, 34(4), 379-404.

Mandik, P. (2014). This is philosophy of mind: An introduction. West Sussex, UK: John Wiley and Sons Inc.

McGinn, C. (1983). The subjective view: Secondary qualities and indexical thoughts. New York, NY: Clarendon Press.

Mulder, D. H. (n.d.). Objectivity. In J. Fieser \& B. Dowden (Eds.), International Encyclopedia of Philosophy. Retrieved August 19, 2019 from https://www.iep.utm.edu/objectiv/ 
The Arbutus Review • $2019 \bullet$ Vol. 10, No. 1 • https://doi.org/10.18357/tar101201918931

Nagel, T. (1974). What is it like to be a bat? The Philosophical Review, 83(4), 435-450. doi: $10.2307 / 2183914$

Nagel, T. (1986). The view from nowhere. New York, NY: Oxford University Press.

Ney, A. (n.d.). Reductionism. In J. Fieser \& B. Dowden (Eds.), International Encyclopedia of Philosophy. Retrieved August 19, 2019 from https://www.iep.utm.edu/red-ism/

Nida-Rümelin, M. (2015). Qualia: The knowledge argument. In E. N. Zalta (Ed.), The Stanford Encyclopedia of Philosophy. Retrieved from https://plato.stanford.edu/archives/sum2015/entries/ qualia-knowledge/

Oppy, G. (1998). Propositional attitudes. In The Routledge Encyclopedia of Philosophy. Taylor and Francis. Retrieved 19 Aug. 2019, from https://www.rep.routledge.com/articles/thematic /propositional-attitudes/v-1. doi:10.4324/9780415249126-V028-1

Particularity [Web Page]. (n.d.). Retrieved August 19, 2019 from https://www.dictionary.com/ browse/particularity

Poole, S. (2016). Rethink: The surprising history of new ideasF. New York, NY: Scribner.

Ramsey, W. (2019). Eliminative materialism. In E. N. Zalta (Ed.), The Stanford Encyclopedia of Philosophy. Retrieved from https://plato.stanford.edu/archives/spr2019/entries/materialismeliminative/

Schlosser, M. (2015). Agency. In E. N. Zalta (Ed.), The Stanford Encyclopedia of Philosophy. Retrieved from https://plato.stanford.edu/archives/fall2015/entries/agency/

Schneider, S. (2013). Non-reductive physicalism and the mind problem. Nôus, 47(1), 135-153. doi:10.1111/j.1468-0068.2011.00847.x

Searle, J. R. (1980). Minds, brains, and programs. Behavioral and Brain Sciences, 3(3), 417-424. doi:10.1017/S0140525X00005756

Searle, J. R. (2010). Why dualism (and materialism) fail to account for consciousness. In R. E. Lee (Ed.) Questioning Nineteenth Century Assumptions about Knowledge, III: Dualism (pp. 5-48). New York, NY: SUNY Press.

Stoljar, D. Physicalism. (2017). In E. N. Zalta (Ed.), The Stanford Encyclopedia of Philosophy. Retrieved from https://plato.stanford.edu/archives/win2017/entries/physicalism/

Tallis, R. (1999). The explicit animal: A defence of human consciousness. New York, NY Palgrave Macmillan. doi:10.1007/978-1-349-27662-2

Van Gulick, R. (1997). Understanding the phenomenal mind: Are we all just armadillos? Part I: Phenomenal knowledge and explanatory gap. In N. Block, O. Flanagan, \& G. Güzeldere (Eds.), The Nature of Consciousness, Philosophical Debates (pp. 559-556). Cambridge, MA: MIT Press.

Wilkes, K. V. (1984). Is consciousness important? The British Journal for the Philosophy of Science $35(3), 223-243$.

Yoo, J. (n.d.). Mental causation. In J. Fieser \& B. Dowden (Eds.) International Encyclopedia of Philosophy. Retrieved August 19, 2019 from https://www.iep.utm.edu/mental-c/ 